\title{
Review: Perpetual Motion: Dance, Digital Cultures, and the Common by Harmony Bench (2020)
}

\author{
Jaleea Price
}

Perpetual Motion: Dance, Digital Cultures, and the Common takes the reader on a journey through a collection of digital dance works that cumulatively reveal a rich, and ongoing, interplay between dance and digital media. Available for purchase as a book and as an openaccess download, Perpetual Motion details an historical evolution of dance's engagement within shared digital media experiences, focusing on the period from 1996 to 2016 . As a reader, I quickly found within these pages a personal connectivity and, in these isolating times, a renewed membership into the global, online corporeal community. With myriad works (re)discovered in each chapter, Perpetual Motion shows us the global impact dance and digital media have had upon each other through shared social relationships and interactions, both on- and off-screen.

Amidst a richly-woven tapestry of philosophical thinking, author Harmony Bench embeds vivid analysis of shared social relationships within digital spaces as "common", in layered definitions. Readers come to understand movement not only as a common resource, but also digital dance itself as a set of "commoning practices". Using the term from theatre scholar Elizabeth Maddock Dillon, Bench constructs examples of these practices as "performative commons" 1 - where artists and viewers collaboratively co-exist in and co-produce shared movement artifacts, across digital media and across bodies. Highly relevant to current social media landscapes, this idea of performative commons is developed and substantiated through analyses shining light on archival markers in dance media history. Traveling through the pages of Perpetual Motion is like unearthing a virtual time capsule and finding layers of digital dance formations - from 1990s interactive screen works to current politically-engaged circulations of viral videos.

Chapter One establishes repetition as a thematic anchor, both in choreographic analysis and conceptual links to early interactive dance-media loops. First exploring CD-ROM examples of limited replay options, Bench later compares iPad apps and iterative screen dance works as more nuanced participatory artifacts in the 1990s (as Bench describes, over this period the invitation to viewer-participants develops, from repeated clicking a 'repeat' button to creating one's own movement material as a factor within the work.) Connecting these works with French philosopher, Jean-Luc Nancy's definition of 'unworking' 2 artifacts, Bench argues that they planted the seeds of future digital-dance commonalities in trends of participation, with YouTube as a favored platform. Those trends are explored throughout subsequent chapters, including: self-recorded dancing in public common spaces in Chapter Two, dancemakers crowdsourcing common material within a diverse global identity in Chapter Three,

The International Journal of Screendance 11 (2020). https://doi.org/10.18061/ijsd.v11i0.7970

(c) 2020 Price. This article is published under a Creative Commons Attribution 4.0 International License (https://creativecommons.org/licenses/by/4.0/) 
and the globalized, gifted re-performing of common digital-dance artifacts in Chapter Four. Each chapter successively builds on the previous writing in weaving through relational developments of the Internet and global dance-cultures.

Continuing with the opening chapter's premise of digital dance as a participatory act, Chapter Two shifts focus to public venues where unexpected airport solos or flash mobs exemplify how "[dance] transforms the affective dimension [of a space]" and "can thus recuperate a sense of the common within public spaces". ${ }^{3}$ Here, Bench intertwines theories on the politics of aesthetics and corporeal appearance in questioning what rights do which bodies have to dance in which public spaces (and non-spaces)? During the post-9/11 restrictions on movement in public spaces of the early 2000s in the USA, much dancing onsite became dancing online, disseminated through early forms of social media and allowing for a redistribution of space, via digital platforms, back into the hands of the collective common. The works examined range from heart-warming videos of solo dancers playfully engaging city-goers, to more politically-charged embodied protests and displays of solidarity, dancing in banks or malls. Bench's analysis reveals that amidst the fun of the flash mob era, there are also "important examples of how... "just" dancing in public can be a deeply political act". 4

Expanding the scope further from public dance in the USA into global perspectives, Chapter Three connects dancing together on social media as a way to create meaning in a common world or a worldly world in Nancy's mondialisation. ${ }^{5}$ In Bench's selected examples of crowdsourced choreographies from diverse movement backgrounds, participants intermingle roles of dance-making, film-making and/or viewing, all to coexist as Nancy's "singular plurality" 6 of individuals within the masses of common digital-dance collectives. In the final chapter, using the 24-Hour "Happiness" music video project as a primary example, Bench analyzes more commercialized online spaces to assert that "at the intersection of gift and market economies, [dance] in digital cultures, ... migrate[s] as a gift of the common." Grounded in anthropological theories, Bench argues that digital platforms support the perpetual motion of shared movement information throughout globalized platforms as gifts of "shared gestures and choreographies ... [that] travel between the culture industry and fans."

As a dance-arts educator, I found many of the curated artifacts in Perpetual Motion to be engaging tools or learning resources. I was delighted by the archaic CD-ROM tidbits unearthed (and sad I couldn't play them - as Bench discusses, the disappearance of these works through obsolescence is itself an important aspect in the study of digitized dance). I was also intrigued by the iPad Apps (which I could download and play!). Bench's unique collection is a valuable resource showcasing pivotal works in a lesser-known history of digital movement-based art. Some of the 90's websites of screendance projects or old gifs and memes were occasionally frustrating in limited viewing access (darn you FlashPlayer!). However, the majority of YouTube videos and short films were still quietly awaiting rediscovery. Many of the works also resonate with sociopolitical contexts that are highly relevant in current global perspectives. Chapter One's purgatory of performing repetitive loops in limited space recalls images of COVID lockdown. Meanwhile the political power of unified bodies in public, from the 2012 Black Lives Matter movement in Chapter Two, can be 
seen re-performing all over the world today. In Chapters Three and Four, almost as a counterperspective to political contexts, the artifacts examined reveal a semblance of shared 'global digital-dance citizenship' amongst practitioner-performers and viewers.

Far from painting social media as a great equalizer in global dance expressions, Bench does raise stinging questions of appropriating culture, and gives voice to legitimate concerns of authorship and attribution regarding crowdsourcing. She also notes the privileged positions of a majority of social media producers, and readily admits that her own specific lens has narrowed the scope of the book's investigations. 'However, my salient feeling after reading this book is that, through "attend[ing] to shifts in dance performance, reception, dissemination, and circulation brought about by popular digital media technologies"7 Bench is offering up a set of questions and approaches that will lend themselves to future analyses of historical, current and future dances in digital spaces. Perpetual Motion accumulates a sense of kinesthetic connections across borders; an empathy and vitality in sharing laughter, and struggles, through digital dance as a common, embodied global language. Bench's research is an important commentary on the evolutionary synergy between digital dance and social media, a process through which common human experiences are shared across global digital cultures.

\section{Author Biography}

Jaleea Price is an international dance-art and film educator with a penchant for movement analysis, biomechanics, and theater tech. She is a neophyte filmmaker and Certified

Movement Analysis candidate with an M.A. in Dance from California State University - Long Beach. When not teaching, teching, or practicing Mandarin, Jaleea can be found binging on screendance, investigating global intersections of Black Lives Matter campaigns, or learning new recipes while living in Asia.

\section{References}

Bench, Harmony. Perpetual Motion: Dance, Digital Cultures, and the Common. Minneapolis: University of Minnesota Press, 2020. https://doi.org/10.5749/j.ctvxw3p32

Cramer, Franz Anton. "Thinking Dance - Jean-Luc Nancy: Goethe Institut." Copyright: Goethe-Institut e. V., Internet-Redaktion April 2015. Translation: Heather Moers.

https://www.goethe.de/en/kul/tut/gen/tan/20509686.html

Maddock Dillon, Elizabeth. New World Drama: The Performative Commons in the Atlantic World, 1649-1849 Durham: Duke University Press, 2014. https://doi.org/10.1215/9780822395737

\section{Notes}

${ }^{1}$ Maddock Dillon, 2014

${ }^{2}$ Bench, 2020: 15

${ }^{3}$ lbid., 17

${ }^{4}$ Ibid., 61

${ }^{5}$ Ibid., 17

${ }^{6}$ Ibid., 101-102

${ }^{7}$ Bench, 187 